quickly displayed these phenomena, to apply a substance which should afford the best and most common antiseptic capable of being administered in bulk without the influence of any other qualities. This was supplied by charcoal.

Sugar, in common with lard and charcoal, possesses powerful antiseptic qualities, combined with a stimulating property ; and in the addition of this constituent the necessity of a stimulus was acknowledged by the old man, in common with the medical profession at large, who have almost uni versally admitted that principle; but unfortunately the mass of the profession (at least in North America) could not admit the axiom without taking leave of their judgment, and administering spirituous liquors to excess, and, in cousequence, many hundreds, to my knowledge, died in the same condition as they had lived, -namely, drunk. I must remark, in passing, that I consider the brandy and laudanum treatment, the unnatural corribination of a narcotic and an inflammatory stimulant, to have been a stain on the intelligence of the profession, - a practice conceived in gross ignorance of the discase if not of the agents themselies. The main feature of cholera is inflammation of the stomach, for instance. I have seen no case in which congestion and inflammation of that organ have not existed. What, then, are the most proper applications to be made to it? for the stomach is in nearly the same circumstances as those of a $\operatorname{limb}$ suffering from phlegmonous inflammation. Administer substances which shall serve the offices of fomentations, poultices, and ointments. This may be decried as quackery, but we are bound in this disease to try every expedient which bears the remotest feature of a rational principle, or is founded upon any recognizable maxim.

I am bound also to state that at the instant of attack, a liberal bleeding, hot fomentations, and the administration of ipecacuanha and antimony, have been successful with my own patients. I have, ever since I lost $m y$ first case (that of a comparion and friend, by the abuse of laudanum and brandy), invariably used the hot fomentation, and no circumstance has occurred to stagger my faith in its efficacy. I am, $\mathbf{S i r}$,

Your obedient servant,

Bristol, Sept. 16, 1835. prevent the ignition of that gas, I trust you will allow me, through the pages of your scientific and much-read publication, to point out some dangerous errors into which, I conceive, he has fallen. The subject is one of great interest to all well-disposed persons, and of immense importance to those who are engaged in coal mining-much valuable property having been destroyed, and hundreds of lives lost, even within the last two years, in all probability by the prevalence of erroneous notions on the subject. I certainly do not think that the tests to which the safety-lamps in the late trial were put were too severe. No test ought to be considered too severe that could be met by any lamp then produced. One of the objects of the Committee was to ohtain the highest security for the miner that could be obtainer in a lamp. Were they then to take lamps that were not even safe to the test of common coal-gas, when one conld be found that would bear the test of hydrogen and atmospheric air?

Amongst other observations of Dr. Clanny is the following:- "Had Sir H. Davy, in his admirable experiments on the inflammable gases of coal.mines, found any gases stronger than the fire-damp or light carburetted hy drogen, he would have no doubt so modified his wire-ganze (without using the objectional medium of glass), that even jet of coal-gas conld not by any chance be driven through it." * * * "All these experiments of Mr. Pereira (therefore) go for nothing, as our pitman can testify." Now, with respect to this modification of the wire-gauzein the Davy-lamp, or in any lamp on its construction, any pitman will readily testify, and with good reason, that this modification of the wire-gauze has been carried to the full extent in all such lamps, which will leave them in any degree useful as a means of affording light. And in Sir $H$. Davy's own pamphlet on fiame, \&c., page 15, it will be found that Sir H. Davy was not so ill informed on this subject as has been represented. Sir $H$. Davy there says, "Some phenomena that 1 observed in the combustion of a blower, induced me to believe that small quantities of olefiant gas might sometimes be evolved in coal-mines with the carburetted hydrogen; I therefore resolved to make all lamps safe to the test of gas produced by the distillation of coal." Sir H. Davy even goes further on this most important point. At page 144 of the same pamphlet, Sir H. Davy says, "If pure hydrogen should be disengaged in any mines, the improbability of which is, however, very great, wire of a finer texture must be employed." Dr. C. says that while in town he made a promise to Mr. Pease and to Mr. Nicholas Wood, who is described by him as not only "an experienced," but as an "accomplished viewer," to analyse some of the most explosive fire-damp of coal-mines in

Sir,-As some parts of Dr. Clanny's let-
ters, which are not altogether personal, relate to his own opinion of the explosive quality of the fire-damp of coal-mines, and to the requisite power of safety-lamps to

\title{
SAFETY-LAMPS AND FIRE-DAMP.
}

To the Editor of THE LANCET. 
this district, which it appears the Doctor has done. Now with reference to his analysis of fire-damp, I beg to remark that from his statement, it might be inferred, that this gas is naturally less inflammable than coal-gas. That it generally appears so when analyzed is true, but to believe that it is always so, is an error, which has no doubt been productive of many of those lamentable accidents that have of late been so frequent and so severely felt in some of the mining districts; and which error therefore cannot be too speedily corrected. Fire-damp in its pure state is called "light carburetted hy.drogen," from its having less carbon to its bulk of hydrogen than the common coal-gas. Corsequently when in its pure state, mixed with a proper proportion of atmospheric air, it approaches, in inflammability, perhaps nearly to hydrogen itself and atmospheric air. Happily for the miner, it is very seldom found in this pure state, and never perhaps can be so, unless suddenly evolved in large quantities. Sir H. Davy states, pp. 30, 31,- "I mixed azote and carbonic acid in different quantities with explosive thixtures of fire-damp, and $I$ found that, even in very small proportions, they diminished the velocity of its inflammability. Azote in the proportion of one to six of an explosive mixture containing twelve of air and one of fire-lamp, deprived it of its power of exploding; and one part of carbonic acid to seven of an explosive mixture, also deprived it of the power of exploding; so that its effects are more remarkable than those of azote." Scveral other eminent men have shown that it is scarcely possible to get two specimens of fire-damp of the same quality. The variations of the quantities of its admixtures, which must always depend materially on local circumstances, it appears sometimes extend to at least 50 per cent. The experimentalist on a small scale is therefore frequently deceived, for he can scarcely ever come a second time to the same conclusion. Indeed he seldom gets it tolerably pure, as it is generally taken within the natural reach of the person employed, where it cannot be otherwise than greatly contaminated with carbonic acid and nitrogen. I can, from my own experience, speak of a great difference in the inflammability of two specimens of this gas. The firedamp which was taken at a height of about twerity-five feet from a sumpt, was so highly inflammable, that its flame readily passed through a Davy lamp; while some taken near the floor of the same mine, at the base of this sumpt, had no material power on the lamp, and perhaps would not have been dangerous with a naked light. These facts show how carefully experiments, or opinions on the subject should be scrutinized. The fire-damp may come in any coal-mine, as it did so lately at the Wallsend Colliery, in a state no doubt far more explosive than it had been there for the prcceding tweive years. But it came, and suddenly swept all away. No man therefore can be expected to be attended to who recommends that any extent of security which can be obtained, should be dispensed with where the smallest want of that which is quite sufficient, is generally attended with destruction.

I shall close my letter, which I now do, that I may not overreach too far, if I have not done so already, on your valuable space, without taking notice of the allusion made by Dr. Clanny to the parties "concerned in uprearing a well-puffed safety-lamp ;" nor to his intended insulting reference to "a pitman," "a lamp manufacturer," or other insinuations which may be considered as personally offensive, and remain, Sir, your obedient servant,

$$
\begin{aligned}
& \text { 61, Queen-street, Cheapside. } \\
& \text { 22nd Sept., } 1835 \text {. }
\end{aligned}
$$

[We have taken the liberty of suppressing from this letter every paragraph which would lead to useless and valueless controversy.-ED. L.]

\section{THE LA NCET.}

\section{London, Saturday, October 10, 1835.}

The very persons who possess less than the least influence in the election of medical officers in our public charities, are of all persons the most likely to be injured by a bad choice of hospital functionaries, and the most certain to be benefited by a good one. Those persons are the patients. The position which they occupy as claimants for the bounty of the charity prevents their admittance to the suffrage, excepting by a mode which must be described on another occasion. Every man, however, of a liberal and benevolent mind,-all those, in fact, who would place elections to public medical offices on a foundation which will ensure to the sick poor, efficient remedial aid, admit in theory the propriety of granting an influential voice in the choice of their medical attendants to the inmates of our national hospitals, for in the hands of those attendants are often placed the awful destinies of life or death. 